\title{
La melancolía hispana, entre la enfermedad, el carácter nacional y la moda social
}

La reflexión que propongo cuenta en su base con dos convicciones que, conforme avanzo en lecturas y reflexiones sobre la melancolía, se me arraigan cada vez más. La primera de ellas: la labilidad del concepto con el que tratamos. Desde el famoso texto del Pseudo-Aristóteles -el Problema XXX-, hasta los más contemporáneos intentos de sustituir la melancolía por otros planteamientos más 'científicos' (como el de depresión, etc.), jamás ha tenido un referente substancial y objetivo, y ha mantenido el mismo aire fantasmal de la tan famosa 'bilis negra' de la teoría humoral tardohipocrática canonizada por Galeno. Como dice Kristeva en un famoso estudio: «El estatuto exacto de estas representaciones psíquicas [...] permanece, en el estado actual de las teorías psicoanalíticas y semiológicas, muy impreciso» ${ }^{1}$. Quizás se deba a ello que el concepto retorne, se revise, se reinterprete cíclicamente en la historia de Occidente, y que, por tanto, Lepenies, autor de Melancolía y sociedad, haya puesto un prólogo a su nueva edición de 1998 titulado «El fin de la utopía y el regreso de la melancolía»². Así que nos encontramos con que, más allá de cualquier intento actual, científico, por eliminar este fantasma de la tradición, siempre amenaza con su regreso tras años o siglos de exilio.

Esto me conduce a la segunda convicción anunciada: la victoria de los Antiguos sobre los Modernos (expresémoslo a la manera de la Querella clásica). La cosmología, la medicina o la antropología arcaicas y fantasmagóricas de la Antigüedad greco-romana se han revelado, para muchos estudiosos del siglo $\mathrm{XX}$ y de comienzos del XXI, como más fecundas para la interpretación de las obras de arte, de las obras literarias, y de los diferentes momentos de la sensibilidad y del gusto europeo que el propio psicoanálisis de Freud, que en la época de entreguerras del siglo XX pasó por ser la clave científica de las enfermedades del alma, de los malestares culturales, e incluso del arte y de la poesía. Así que, la ciencia antigua de Aristóteles, de Hipócrates y de Galeno, que el Renacimiento no dudó en revalorizar, ha encontrado en la actualidad una nueva fertilidad heurística para el estudio de las artes, de la literatura, del gusto y de la sensibilidad.

Partiendo de estas bases epistemológicas, quisiera echar una ojeada a la historia cultural (principalmente literaria) de la melancolía hispana, que, como indi-

\footnotetext{
Julia Kristeva, Soleil noir. Dépression et mélancolie, París, Gallimard, 1987, p. 31.

Wolf LEPENIES, Melancholie und Gesellschaft, Fráncfort del Meno, Suhrkamp, 1998.
} 
co en el título, es un concepto que se mueve entre la enfermedad, el carácter nacional y la moda social.

Es habitual que nos topemos con la convicción social de que la melancolía ha sido durante siglos una característica del español, un carácter (el español) fraguado en la época imperial, y que encontró su mejor expresión en la literatura y en las artes de los Siglos de Oro. Pero se imponen una serie de matices a tan asumido planteamiento. Si atendemos pormenorizadamente a nuestra literatura de los siglos XVI y XVII, vemos que en realidad los melancólicos de nuestras obras literarias sufren un importante cambio con el paso del tiempo, un cambio que va de la enfermedad al carácter. Ese cambio es el que refiere Földényi como situación común en todo Occidente: el paso del temperamento melancólico renacentista al sentimiento de tristeza barroco, un modo de mirar y de estar en el mundo común a gran parte de la Europa barroca, principalmente Inglaterra y Alemania ${ }^{3}$. Pero en España ese sentimiento común europeo, al parecer, fragua en carácter nacional, por lo que se hace un asunto más interesante todavía para nosotros, españoles, y para los que nos miran desde fuera. Tan interesante resulta que Fumaroli, recientemente, construye todo un artículo cuya tesis es la prefiguración del carácter nacional francés à rebours de lo caracterológicamente español (entroncando con el gran Montaigne, el primero en darse cuenta de la moda literaria de la melancolía y el primero en denostarla); y él dice: «Enfermedad nacional en Inglaterra, moralmente destructiva o literariamente fecunda, la melancolía era tenida en la misma época por los españoles como el asiento humoral, sano y superior de su carácter nacional» ${ }^{4}$.

A quien debemos la unión y el paso de la melancolía entendida como enfermedad a la melancolía considerada como carácter nacional español es, según el propio Fumaroli, a Huarte de San Juan:

Huarte no se contentaba con clasificar a los individuos según su temperamento y la capacidad de espíritu que tal temperamento les permitía. Combinando la astrología de las 'influencias' y de las 'conjunciones' fastas o nefastas, con la física de los cuatro elementos, la medicina de los cuatro humores, la tipología de los temperamentos, y la caracterización de los terrenos y los climas, proponía una clasificación de los caracteres nacionales europeos, a la cabeza de los cuales situaba a los Españoles ${ }^{5}$.

Juan Huarte de San Juan (1529-1589) es el médico y filósofo español que escribió un Examen de ingenios para las ciencias, de gran fama en toda la Europa

\footnotetext{
Cf. László FöLDÉNYI, Melancolía, Barcelona, Círculo de Lectores-Galaxia Gutenberg, 1996, pp. 163 y ss.

4 Marc Fumaroli, «La mélancolie et ses remèdes: la reconquête du sourire dans la France classique», en: Jean ClaIR (dir.), Mélancolie, génie et folie en Occident, París, Gallimard, 2005, p. 211.

5 Ibídem, p. 211. La cursiva es nuestra.
} 
de su tiempo. Nace su pensamiento de un argumento teológico: la expulsión de Adan y Eva del Paraíso terrenal. Nuestros primeros padres fueron creados por Dios con todas las perfecciones y vivieron en un ambiente perfectamente templa$d o$, el del Paraíso, que no contenía elemento alguno capaz de dañar la perfección original, la perfección prototípica de la primera pareja. Una vez expulsados del Paraíso, condenados a vivir en condiciones terrenales adversas, con variantes geográficas, climáticas y alimenticias, tales circunstancias comenzaron a actuar sobre su cuerpo y el de sus descendientes produciendo cambios que hoy podríamos llamar de carácter psicosomático. Las diferencias ambientales actúan sobre los cuerpos y sobre los aparatos psíquicos de los hombres, originando tantos ingenios distintos como individuos existen. Entiende Huarte ingenio por el conjunto de habilidades psíquicas de un individuo. Lo que a nuestro doctor le interesa es dilucidar los parámetros que permiten la determinación de los distintos tipos de ingenios, con una intención práctica: que en los reinos de España se obligue a cada ingenio a elegir la actividad profesional que le es idónea.

Huarte utiliza para la detección de los distintos ingenios esquemas cuaternarios, basados en los cuatro elementos (la tierra, el fuego, el aire y el agua), en las cuatro cualidades primeras (la sequedad, el calor, la humedad y el frío), los que producen, en sus variadas combinaciones, los cuatro temperamentos (sanguíneo, colérico, flemático y melancólico). Vemos que hay en Huarte un estructuralista avant la lettre, como dice Harald Weinrich en su prólogo a la edición de Guillermo Serés del Examen $^{6}$. Toma, pues, como base de su entendimiento de la melancolía (uno de los cuatro temperamentos) la clásica teoría de los humores (bilis negra, sangre, bilis clara y flema) en relación con los temperamentos (melancólico, sanguíneo, colérico y flemático). De este modo, las diferentes mezclas de los humores definen a los individuos. Huarte es galenista. También sigue a Aristóteles, considerando que los humores ejercen su efecto bien por el calor bien por el frío. Los humores, sin estas dos cualidades, no son capaces de manifestar su acción (cap. V):

De manera que el rezar, contemplar y meditar enfría y deseca el cuerpo y lo hace melancólico. Y, así, dijo Aristóteles: cur homines qui ingenio claruerunt, vel in studiis philosophiae, vel in republica administranda, vel in carmine pangendo, vel in artibus exercendis, melancholicos omnes fuisse videantur??

Las acciones del rezo y la meditación o la reflexión intelectual conllevan un gasto de calor que enfría el cuerpo y permite la subida del humor a la inteligencia, hiriendo gravemente la imaginación. Es ésta una concepción médico-filosófica

Juan HuARte de SAN JuAn, Examen de ingenios para las ciencias, p. 13.

http://electroneubio.secyt.gov.ar/Juan_Huarte_de_San_Juan_Examen_de_ingenios.htm 
que interpreta, con las bases de la medicina clásica que viene del Problema XXX y de Galeno, la melancolía como un desequilibrio anormal en el cuerpo humano que lo hace proclive a la enfermedad, bien sea la locura, bien sea un abatimiento de cuerpo y alma, bien sea una tristeza sin razones, bien sea una huida híspida de las relaciones con sus congéneres, todo ello unido a diferentes manifestaciones de problemas de gases, de malas digestiones, de insomnio, de ataque de gota, etc.

Este cuadro que relaciona la melancolía con la enfermedad es el que alimenta gran parte de la literatura española del Renacimiento y del Manierismo. Hay incluso un fragmento de la obra de Huarte que se ha relacionado con el personaje de don Quijote, siendo considerado (por algunos estudiosos), el ejemplo que da nuestro médico del XVI, como el origen del personaje cervantino ${ }^{8}$. El texto de Huarte al que me refiero es del cap. IV [VII de 1594]:

Pero, para que se entienda por experiencia que si el celebro tiene el temperamento que piden las ciencias naturales no es menester maestro que nos enseñe, es necesario advertir en una cosa que acontesce cada día. Y es que si el hombre cae en alguna enfermedad por la cual el celebro de repente mude su temperatura (como es la manía, melancolía y frenesía) en un momento acontesce perder, si es prudente, cuanto sabe, y dice mil disparates; y si es nescio, adquiere más ingenio y habilidad que antes tenía.

En confirmación de lo cual no puedo dejar de referir lo que pasó en Córdoba el año 1570, estando la corte en esta ciudad, en la muerte de un loco cortesano que se llamaba Luis López; éste, en sanidad, tenía perdidas las obras del entendimiento, y de lo que tocaba a la imaginativa decía gracias y donaires de mucho contento; a éste le dio una calentura maligna de tabardillo, en medio de la cual vino de repente a tanto juicio de discreción, que espantó a toda la corte: por la cual razón le administraron los santos sacramentos, y testó con toda la cordura del mundo, y así murió, invocando la misericordia de Dios y pidiendo perdón de sus pecados.

En realidad, el ejemplo del loco Luis López es una intercalación posterior.

El ejemplo por excelencia en la literatura, para ver la unión entre enfermedad y melancolía durante el Renacimiento y el Manierismo español, lo encontramos en algunos de los personajes cervantinos. No sólo don Quijote. Pensemos en otros personajes de la misma novela, como el loco Cardenio (loco por amor) o el compulsivo protagonista del Curioso impertinente. Y fuera del Quijote, recordemos al loco de vidrio, al Tomás Rodaja de El Licenciado Vidriera. O a algún otro personaje del Persiles. Fumaroli nos dice en su artículo:

8 Cf. Juan Bautista Avalle-Arce, Don Quijote como forma de vida, en concreto el cap. IV, «La locura de vivir», http://www.cervantesvirtual.com/servlet/SirveObras/56921623170258354261157/index.htm 
El don Quijote de Cervantes, si bien tiene el espíritu turbado por las quimeras de los libros de caballerías, en los momentos de respiro que tiene su locura, este gran melancólico de raza enuncia los aperçus fulgurantes de un apóstol o las sentencias doradas propias de un sabio 9 .

Junto a don Quijote, los otros personajes ya mencionados. A García Gibert debemos un detenido paseo por la melancolía en la obra cervantina, desde La Galatea (que es «una sucesión, hasta cierto punto previsible, de melancolizados por amor -Timbrio, Silerio, Galercio, y tantos otros- según los patrones que dictaba el género y la tradición») ${ }^{10}$, pasando por las comedias cervantinas de cautivos («terreno abonado para la aparición de personajes y situaciones melancólicas, motivados por la falta de libertad») ${ }^{11}$ y llegando a sus novelle, exentas (como El Licenciado Vidriera) o incrustadas en su magno Quijote, «una obra concebida desde y para la melancolía» ${ }^{12}$.

Pocos personajes escapan en el Quijote a la melancolía. El propio Sancho, sanguíneo, cachazudo, aparece «con melancólico semblante» en el cap. XXXVII de la primera parte. Previamente, en el cap. XVIII, tras la aventura de los rebaños, se le describe «de pechos sobre el asno, con la mano en la mejilla, en guisa de hombre pensativo». El propio Rocinante es una versión animalizada de la melancolía. Y, por supuesto, como venimos repitiendo, don Quijote. La suya es una melancolía que comienza siendo un tenue murmullo y acaba convirtiéndose en una melodía claramente perceptible ${ }^{13}$, con su punto de inflexión en el cap. XLIV de la segunda parte:

Cuéntase, pues, que apenas se hubo partido Sancho, cuando don Quijote sintió su soledad, y si le fuera posible revocarle la comisión y quitarle el gobierno, lo hiciera. Conoció la duquesa su melancolía y preguntole que de qué estaba triste, que si era por la ausencia de Sancho, que escuderos, dueñas y doncellas había en su casa que le servirían muy a satisfación de su deseo.

-Verdad es, señora mía -respondió don Quijote-, que siento la ausencia de Sancho, pero no es esa la causa principal que me hace parecer que estoy triste, y de los muchos ofrecimientos que Vuestra Excelencia me hace solamente acepto y escojo el de la voluntad con que se me hacen, y en lo demás suplico a Vuestra Excelencia que dentro de mi aposento consienta y permita que yo solo sea el que me sirva ${ }^{14}$.

\footnotetext{
9 Marc Fumaroli, «La mélancolie et ses remèdes: la reconquête du sourire dans la France classique», en: Jean CLAIR (dir.), Mélancolie, génie et folie en Occident, cit., pp. 211-212.

10 Javier GARcía GiBerT, Cervantes y la Melancolía. Ensayos sobre el tono y la actitud cervantinos, Valencia, Alfons el Magnànim, 1997, p. 83.

11 Ibídem, p. 86.

12 Ibídem, p. 92.

3 Cf. ibídem, p. 102.

14 http://cvc.cervantes.es/obref/quijote/edicion/parte2/cap44/default.htm\#arriba
} 
Sin duda, todos estos resultados literarios tienen en su base al propio autor. Recordemos cómo lo encuentra su amigo gracioso y bien entendido en el Prólogo a la primera parte del Ingenioso hidalgo:

Muchas veces tomé la pluma para escribille [el prólogo], y muchas la dejé, por no saber lo que escribiría; y estando una suspenso, con el papel delante, la pluma en la oreja, el codo en el bufete y la mano en la mejilla, pensando lo que diría, entró a deshora un amigo mío, gracioso y bien entendido, el cual, viéndome tan imaginativo, me preguntó la causa, y, no encubriéndosela yo, le dije que pensaba en el prólogo que había de hacer a la historia de don Quijote, y que me tenía de suerte que ni quería hacerle, ni menos sacar a luz las hazañas de tan noble caballero.

-Porque ¿cómo queréis vos que no me tenga confuso el qué dirá el antiguo legislador que llaman vulgo cuando vea que, al cabo de tantos años como ha que duermo en el silencio del olvido, salgo ahora, con todos mis años a cuestas, con una leyenda seca como un esparto, ajena de invención, menguada de estilo, pobre de concetos y falta de toda erudición y doctrina, sin acotaciones en las márgenes y sin anotaciones en el fin del libro, como veo que están otros libros, aunque sean fabulosos y profanos, tan llenos de sentencias de Aristóteles, de Platón y de toda la caterva de filósofos, que admiran a los leyentes y tienen a sus autores por hombres leídos, eruditos y elocuentes? ${ }^{15}$.

Vemos, pues, a Cervantes en pleno acceso de melancolía ante las dudas de su creatividad. Un entendimiento del creador tal y como nos lo mostrara Ficino en su De vita triplici o como mostrara a la propia Melancolía el pintor Durero por la misma época. Tampoco la obra aparece ajena a los conceptos melancólicos, pues Cervantes, como nos recuerda García Gibert, «se complace en dirigirlo [El Quijote], more terapéutico, a un público de melancólicos», y recuerda, para avalarlo, el consejo del ya mencionado amigo gracioso y bien entendido: «Leyendo vuestra historia, el melancólico se mueva a risa» ${ }^{16}$.

Si bien en el siglo XVI hay restos medievales, como sucede en la obra de Teresa de Jesús ${ }^{17}$, y luego en el XVIII habrá restos de la relación entre enfermedad

15 http://cvc.cervantes.es/obref/quijote/edicion/parte1/prologo/default.htm

16 Javier GARCía GiBERT, Cervantes y la Melancolía. Ensayos sobre el tono y la actitud cervantinos, cit., p. 90. Cf. Alan S. Trueblood, «La risa en el Quijote y la risa de don Quijote», Cervantes: Bulletin of the Cervantes Society of America, 4.1 (1984), pp. 3-23. http://www.h-net.org/ cervantes/csa /artics84/truebloo.htm

17 El cap. VII de Las fundaciones, el titulado «De cómo se han de haber con las que tienen melancolía. Es necesario para las preladas», está escrito en San José de Salamanca, en 1573, antes de la publicación del Examen de Huarte (1575). En este capítulo se mezclan la concepción renacentista de melancolía como enfermedad y la medieval de la intervención diabólica. http://www.mercaba.org/FICHAS/Santos/ TdeJesus/fundaciones_02.htm\#CAPÍTULO\%207 
y melancolía, como en Torres Villarroel ${ }^{18}$, podemos generalizar que los melancólicos de nuestra literatura responden primero a la visión renacentista de progenie ficiniana y de colorido local huartino, para quienes la melancolía era una enfermedad propia de seres especiales (de intelectuales y creadores, donde encontramos, en cóctel con dicha enfermedad, los otros ingredientes de la soledad orgullosa del intelectual y de la angustia creadora provocada en el Renacimiento por la tensión entre el pasado clásico y el futuro que pretendía resolver dicha tensión). Posteriormente, mediado el siglo XVII, se fraguará la manifestación del melancólico barroco, el que lo es por visión del mundo (el gesto del universal desengaño), por carácter e incluso por moda. Especialmente en España, es el momento de la fragua del melancólico carácter nacional, que según señala Fumaroli también tiene su origen en Huarte.

Ciertamente Huarte no sólo tiene interés en detectar el ingenio particular de cada joven español para dirigir su formación hacia la actividad que mejor le conviene (más un estudiar por la fuerza -lo que tendría en nuestros días pocos seguidores- que una orientación profesional $)^{19}$, también se preocupa por las analogías y paralelismos caracterológicos, en relación con los climas y circunstancias especiales de los pueblos europeos, haciendo una clasificación general que tan poco gusta a Fumaroli y donde los españoles llevamos la voz cantante. Escuchemos sus propias palabras, en el cap. VIII (X) de su Examen, y entenderemos el disgusto de Fumaroli:

Al segundo problema se responde que, buscando Galeno el ingenio de los hombres por el temperamento de la región que habitan, dice que los que moran debajo el Septentrión todos son faltos de entendimiento; y los que están sitia-

18 Como resume José Luis PeseT, en Genio y desorden, Valladolid, Cuatro, p. 81 (que tiene un capítulo dedicado a Torres Villarroel, principalmente a su Vida): «Fueron mútiples las causas buscadas a esa tristeza [la que lo embarga en el quinto 'trozo' de su vida] por los médicos: sífilis, humores, hipocondría, obstrucciones, brujas, demonios, hechizos, pasiones, amores... Y también fueron diversos los tratamientos: purgas, sangrías, cantáridas, sanguijuelas, ventosas, jeringazos, fregaduras, unturas, lavatorios, emplastos, y drogas como la quina, la triaca o el láudano». Pero en Villarroel también la melancolía significa tristeza y basta para corroborarlo ir a textos suyos como el siguiente de Visiones y visitas de Torres con don Francisco de Quevedo por la Corte, su verdadera obra maestra, y donde se dice:

Sin susto de cosa de esta vida, llamé al sueño; y en breve espacio de si viene o no viene, me pintaba la consideración depostrada (¡válgame Dios, qué acuerdo tan natural!) las parecidas imágenes de cama y sepultura, muerte y sueño, acreditándome este desengaño mi memoria con aquel dístico del gran Nasón, que bien sé que es suyo, pero no me acuerdo ahora en qué elegía lo colocó: Stulte, quid est sommus gelidae nisi mortis imago? / Multa quiescundi tempora fata dabunt. Pero con un filósofo descuido me sacudí de esta melancolía, considerando que aunque el sueño es muerte, era para mí entonces el dormir media vida. (http:// www.cervantesvirtual.com /servlet /SirveObras/ 02405029767028830976613/p0000001.htm\#I_4_)

Claramente esa melancolía que se sacude no es sino una serie de pensamientos tristes que relacionan el sueño con la muerte, como constatan los versos de Ovidio: «¿Qué es el sueño, loco, sino la imagen de la fría muerte? Los Hados te darán largo tiempo para el descanso».

19 Cf. Antonio SimONEnA ZABALEGUI, «Un precursor de la orientación profesional: El doctor Juan de Huarte», http://www.euskomedia.org/PDFAnlt/congresos/04055066.pdf 
dos entre el Septentrión y la tórrida zona son prudentísimos. La cual postura responde puntualmente a nuestra región, y es cierto así. Porque España, ni es tan fría como los lugares del Norte, ni tan caliente como la tórrida zona. La mesma sentencia trae Aristóteles preguntando por qué los que habitan tierras muy frías son de menos entendimiento que los que nacen en las más calientes; y en la respuesta trata muy mal a los flamencos, alemanes, ingleses y franceses, diciendo que su ingenio es como el de los borrachos, por la cual razón no puede inquirir ni saber la naturaleza de las cosas. Y la causa de esto es la mucha humidad que tienen en el celebro y en las demás partes del cuerpo; y así lo muestran la blancura del rostro y el color dorado del cabello, y que por maravilla se halla un alemán que sea calvo; y con esto, todos son crecidos y de larga estatura, por la mucha humidad, que hace dilatables las carnes. Todo lo cual se hace al revés en los españoles: son un poco morenos, el cabello negro, medianos de cuerpo, y los más los vemos calvos; la cual disposición dice Galeno que nace de estar caliente y seco el celebro. Y si esto es verdad, forzosamente han de tener ruin memoria y grande entendimiento; y los alemanes, grande memoria y poco entendimiento. Y, así, los unos no pueden saber latín, y los otros lo aprenden con facilidad. La razón que trae Aristóteles para probar el poco entendimiento de los que habitan debajo de Septentrión es que la mucha frialdad de la región revoca el calor natural adentro por antiparistasis, y no le deja disipar. $\mathrm{Y}$, así, tiene mucha humidad y calor, por donde juntan gran memoria para las lenguas, y buena imaginativa, con la cual hacen relojes, suben el agua a Toledo, fingen maquinamientos y obras de mucho ingenio, las cuales no pueden fabricar los españoles por ser faltos de imaginativa. Pero metidos en dialéctica, filosofía, teología escolástica, medicina y leyes, más delicadezas dice un ingenio español en sus términos bárbaros, que un extranjero sin comparación, porque sacados éstos de la elegancia y policía con que lo escriben, no dicen cosa que tenga invención ni primor. En comprobación de esta doctrina, dice Galeno in Scithiis, unus vir factus est philosophus: Athenis autem multi tales; como si dijera: «En Escitia (que es una provincia que está debajo el Septentrión) por maravilla sale un hombre filósofo, y en Atenas todos nacen prudentes y sabios». Pero aunque a estos septentrionales les repugna la filosofía y las demás ciencias que hemos dicho, viéneles muy bien las matemáticas y astrología, por tener buena imaginativa ${ }^{20}$.

El melancólico por carácter está claramente manifestado en El Criticón de Gracián, y también en Quevedo, y en Góngora; pero, si el melancólico enfermo se manifiesta paradigmáticamente en la obra de Cervantes, el melancólico como carácter español se observa constantemente en El Criticón, donde incluso se sigue la teoría huartina de las edades. Expone Huarte: 
La última edad del hombre - dice el cap. V (1594)- es la vejez; en la cual está el cuerpo frío y seco, y con mil enfermedades y flaco: todas las potencias perdidas, sin poder hacer lo que antes solían. Pero, con ser el ánima racional la mesma que fue en la puericia, adolescencia, juventud, consistencia y vejez, sin haber recibido ninguna alteración que le debilitase sus potencias, venida a esta última edad y con este temperamento frío y seco, es prudentísima, justa, fuerte y con temperancia; y aunque al hombre se han de atribuir estas obras, pero el ánima es el primer movedor, conforme aquello: anima est principium intelligendi. Todo el tiempo que el cuerpo está poderoso, con fuertes facultades vitales, naturales y animales, acuden muy pocas virtudes morales al hombre; pero en perdiendo las fuerzas, luego el ánima crece en virtudes. Parece que quiso sentir esto san Pablo cuando dijo: virtus in infirmitate perficitur; como si dijera: «La virtud y fuerzas del ánima racional se perficionan cuando el cuerpo está enfermo». Y así parece, porque en ninguna edad está el cuerpo más flaco que en la vejez, ni el ánima más libre y suelta para obrar conforme a razón.

Pero con todo eso, cuenta Aristóteles seis vicios que tienen los viejos por razón de la frialdad que el hombre tiene en esta edad. Lo primero son cobardes, porque el ánimo y valentía consiste en el mucho calor y sangre del corazón, y los viejos tienen poca y muy fría. Lo segundo son avarientos, y guardan el dinero más de lo que es menester; porque, estando ya en los postreros tercios de la vida y que la razón les había de dictar que con poca hacienda podrían pasar, entonces les crece más la codicia, como si estuvieran en la niñez y considerando que les restaba cinco edades por pasar y que era bien guardar con qué comprar de comer. Lo tercero son sospechosos; y no sé la razón por qué Aristóteles lo llama vicio, siendo verdad que esto les nace de haber visto por experiencia tantas maldades de los hombres, y acordándose de los vicios y pecados que ellos propios cometieron en su mocedad; y, así, viven siempre con recato, sabiendo que hay poco que fiar de los hombres. Lo cuarto son de mala esperanza y jamás piensan que los negocios han de suceder bien; y de dos o tres fines que pueden tener, siempre eligen el peor y aquél están esperando. Lo quinto son desvergonzados; porque la vergüenza, dice Aristóteles, pertenece a la sangre; y, como los viejos carecen de este humor, no pueden ser vergonzosos. Lo sexto son incrédulos: jamás piensan que les dicen verdad, trayendo a la memoria los embustes y engaños de los hombres y lo que han visto en el mundo en el largo discurso de su vida. Las virtudes contrarias (dice Aristóteles) tienen los mozos. Son animosos, liberales, jamás sospechan mal, son de buena esperanza, vergonzosos, y fáciles de persuadir y creer $^{21}$.

La tercera parte de El Criticón está dedicada a recorrer los paisajes de Vejecia, que así denomina Gracián al discurrir por la vejez. Dice al comienzo de dicha tercera parte: 
Estaban ya nuestros dos peregrinos del mundo, los andantes de la vida, al pie de los Alpes canos, comenzando Andrenio a dar en el blanco [encanecer], cuando Critilo en los dejos de cisne. Era la región tan destemplada y tan triste que, entrados en ella, a todos se les heló la sangre.

-Éstas -decía Andrenio- más parecen puertas de la muerte que puertos de la vida $^{22}$.

Y más adelante:

-¡Qué región tan malhumorada es ésta! -se lamentaba Andrenio.

-¡Y qué malsana! -añadió Critilo-. Trocáronse los fervores de la sangre en horrores de la melancolía, las carcajadas en ayes: todo es frialdad y tristeza.

Esto iban melancólicamente discurriendo ${ }^{23}$.

La melancolía aparece claramente como equivalente de tristeza. Y poco más adelante se confirma esto cuando, hablando de la doblez propia de la vejez (y considerando a todos los viejos como Janos), dice: «Veréis la una faz muy humana, cuando la otra muy grave; tan jovial ésta cuan saturnina aquélla» ${ }^{24}$. Y no es que ignore Gracián la teoría de los humores, pues la tiene, poco después, en mente, cuando, en un episodio muy quevedesco entre un amo (muy remendado de miembros) y su criado (asustando de verlo tan descoyuntado al desnudarse), comenta Gracián del amo: «Mas éste, que debía tener mejor humor que humores» 25 .

Tal y como hemos enunciado antes, con Gracián se ejemplifica a la perfección el paso de melancolía como enfermedad a melancolía como carácter humano (que no temperamento, el matiz es necesario pues en la tradición el temperamento está unido a los humores del cuerpo y su proporción en el mismo). Ahora ser melancólico es mostrar severidad y tristeza ante el mundo y ante los demás hombres. Por eso dice en un momento determinado el zahorí, que todo lo sabe ver en los hombres a los que mira:

-Otra cosa más, que he topado muchos que no tenían la lengua trabada con el corazón, ni los ojos unidos con el seso, con dependencia dél; otros, que no tienen hiel.

-iQué linda vida pasarán ésos! -dijo Critilo.

-Sí, porque nada sienten, de nada se consumen ni melancolizan. Pero lo que es más de admirar, que hay algunos que no tienen corazón.

-Pues ¿cómo pueden vivir?

-Antes, más y mejor, sin cuidados: que corazón se dijo del curarse y tener cuidados. A los tales nada les da pena, no se les viene a consumir como el célebre

22 http://es.wikisource.org/wiki/El_Critic\%C3\%B3n._Tercera_parte:_Crisi_1

23 http://es.wikisource.org/wiki/El_Critic\%C3\%B3n._Tercera_parte:_Crisi_1

24 http://es.wikisource.org/wiki/El_Critic\%C3\%B3n._Tercera_parte:_Crisi_1

25 http://es.wikisource.org/wiki/El_Critic\%C3\%B3n._Tercera_parte:_Crisi_1 
duque de Feria, que cuando llegaron a embalsamarle le hallaron el corazón todo arrugado y consumido, conque le tenía grande. Yo veo si está sano y de qué color, si amarillo de envidia, y si negro de malicia; percibo su movimiento y me estoy mirando hacia dónde se inclina. Las más cerradas entrañas están a mis ojos muy patentes y descubro si están gastadas o enteras; la sangre veo en sus venas y advierto el que la tiene limpia, noble y generosa. Lo mismo puedo decir del estómago: luego conozco qué estómago le hacen a cualquiera los sucesos, si puede digerir las cosas. Y me río las más veces de los médicos, que estará el mal en las entrañas y ellos aplican los remedios al tobillo, procede el mal de la cabeza y recetan el untar los pies. Veo y distingo clarísimamente los humores, y el de cada uno, si está o no de buen humor, observándolo para la hora del despacho y conveniencia; si reina la melancolía, para remitirlo a mejor sazón; si gasta cólera o flema ${ }^{26}$.

Aquí lo puramente fisiológico se ha vuelto moral: la sangre limpia (la obsesión hispana por la limpieza de sangre) es en realidad la noble y generosa, y el buen estómago de algunos lo es porque digieren cualquier cosa, y la amarillez es por envidia y lo negro es por malicia. Y finalmente los humores los relaciona con el buen o mal humor. Por tanto el reino de la melancolía es el reino de la tristeza y de las razones que la provocan. Y el recurrir a la tradición de los humores es más por juego intelectual que por consideración real de tales conocimientos. El melancolizar como actitud ante la vida y como carácter humano está generalizado en el pueblo español.

Insistamos en que además está unido el término melancolía a los paisajes de la tercera y última parte del Criticón. Cuando ven los peregrinos de la vida por primera vez el palacio de Vejecia, se dice:

-He allí -dijo el Jano- el antiguo palacio de Vejecia.

-Bien se da a conocer -le respondieron- en lo melancólico y desapacible.

Y habitualmente se insiste en la relación melancolía/tristeza. Cuando son llevados los peregrinos al palacio de la Alegría, se describe una fuente prodigiosa que brota en el centro de uno de sus patios:

Sea lo que fuere, lo que yo sé es que causa prodigiosos efectos, y todos de consuelo, porque yo vi un día traer no menos que una gran princesa (se dijera lansgravia o palatina) perdida de melancolía, sin saber ella misma de qué ni por qué, que a no ser eso no fuera necia. Habíanle aplicado dos mil remedios, como son galas, regalos, saraos, paseos y comedias, hasta llegar a los más eficaces, cuales son fuentes de oro potable, digo de doblones, tabaquillos de joyas, ces- 
tillos de perlas; y ella, siempre triste que necia, enfadada de todo y enfadando a todos, que ni vivía ni dejaba vivir, de modo que llegó rematada de impertinente. Pues os aseguro que luego que bebió del eficacísimo néctar, depuesta la ceremoniosa autoridad regia, se puso a bailar, a reír y cantar, diciendo que se iba hacia las alturas ${ }^{27}$.

Apenas un poco después, continúa el texto: «Y eso es nada, que yo le vi al más severo Catón, al español más tétrico, dar carcajadas en bebiéndole, que por eso le llamaron los italianos alegra core» ${ }^{28}$. El paso desde el caso particular (el de la princesa melancólica, que parece salida de un relato pastoril) al general (el del carácter melancólico español) es evidente. Se deduce de lo dicho, que todos los españoles son tétricos y que al más de ellos lo vio el relator, una vez que hubo bebido en la fuente, trocado en un hombre de alegre corazón. Todos los españoles son, pues, severos Catones. Lo que implica: censores, serios, honestos (a Catón lo hicieron famoso sus altos valores morales y su virtud incorruptible) y también se hace evidente en el texto una relación entre hombre sabio (Catón) y melancolía.

Pero incidamos en el carácter melancólico del español. Gracián va haciendo, a la zaga de la caracterología de Huarte, todo un panorama contrastivo del ser español con respecto a otras nacionalidades europeas. Y aún más, de los diferentes caracteres regionales. Así, en la crisi tercera de esta misma tercera parte dice:

Pero lo más es que, en viendo a cualquiera, le atinaba la nación; y así, de un invencionero dijo:

-Éste, sin más ver, es italiano.

De un desvanecido, inglés; de un desmazalado, alemán; de un sencillo, vizcaíno; de un altivo, castellano; de un cuitado, gallego; de un bárbaro, catalán; de un poca cosa, valenciano; de un alborotado alborotador, mallorquín; de un desdichado, sardo; de un tozudo, aragonés; de un crédulo, francés; de un encantado, danao [danés]; y así de todos los otros. No sólo la nación, pero el estado y el empleo adevinaba ${ }^{29}$.

Poco más adelante, todavía en esta misma crisi, dedica amplio espacio a Germania:

-Extraño dejo ha sido el de Alemania -decía Andrenio.

Y Critilo:

-Sí, cual yo me lo imaginaba.

27 http://es.wikisource.org/wiki/El_Critic\%C3\%B3n._Tercera_parte:_Crisi_2

$28 \mathrm{http} / / /$ es.wikisource.org/wiki/El_Critic\%C3\%B3n._Tercera_parte:_Crisi_2

29 http://es.wikisource.org/wiki/El_Critic\%C3\%B3n._Tercera_parte:_Crisi_3 
- ¿Qué os ha parecido de aquella tan extendida provincia, la mayor sin duda de Europa? Decidlo en puridad.

-A mí -respondió Andrenio-, lo que más me ha contentado hasta hoy.

Y Critilo:

-A mí, la que menos.

-Por eso no se vive en el mundo con un solo voto.

$-i$ Qué te ha agradado a ti más en ella?

-Toda, de alto a bajo.

-Querrás decir Alta y Baja.

-Eso mismo.

-Sin duda que su nombre fue su definición, llamándose Germania, a germinando, la que todo lo produce y engendra, siendo fecunda madre de vivientes y de víveres y de todo cuanto se puede imaginar para la vida humana.

-Sí -replicó Critilo-, mucho de extensión y nada de intención, mucha cantidad y poca calidad.

${ }_{-}$Eh!, que no es una provincia sola -proseguía Andrenio-, sino muchas que hacen una; porque si bien se nota, cada potentado es casi un casi rey y cada ciudad una corte, cada casa un palacio, cada castillo una ciudadela, y toda ella un compuesto de populosas ciudades, ilustres cortes, suntuosos templos, hermosos edificios y inexpugnables fortalezas.

-Eso mismo hallo yo -dijo Critilo- que la ocasiona su mayor ruina y su total perdición, porque cuantos más potentados, más cabezas; cuantas más cabezas, más caprichos, y cuantos más caprichos, más disensiones; y como dijo Horacio, lo que los príncipes deliran, los vasallos lo suspiran.

-No me puedes negar-dijo Andrenio- su abundancia y su opulencia. Mira qué abastecida de todo, que si dicen España la rica, Italia la noble, también Alemania la harta. ¡Qué abundante de granos, de ganados, pescas, cazas, frutos y frutas! ¿Qué rica de minerales! ¡Qué vestida de arboledas! ¡Qué adornada de bosques, hermoseada de prados! ¡Qué surcada de caudalosos ríos, y todos navegables! De tal suerte que tiene más ríos Alemania que las otras provincias arroyos, más lagos que las otras fuentes, más palacios que las otras casas, y más cortes que las otras ciudades.

-Así es -dijo Critilo-, yo lo confieso, mas en eso mismo hallo yo su destruición y que su misma abundancia la arruina, pues no hace otro que ministrar leña al fuego de sus continuas guerras en que se abrasa, sustentando contra sí muchos y numerosos ejércitos: lo que no pueden otras provincias, especialmente España, que no sufre ancas.

-Pero viniendo ya a sus bellos habitadores -dijo el Acertador-, ¿cómo quedáis con los alemanes?

-Yo muy bien -dijo Andrenio-. Hanme parecido muy lindamente, son de mi genio; engáñanse las demás naciones en llamar a los alemanes los animales, y me atrevo a decir que son los más grandes hombres de la Europa.

-Sí -dijo Critilo-, pero no los mayores. 
-Tiene dos cuerpos de un español cada alemán.

-Sí, pero no medio corazón.

-iQué corpulentos!

-Pero sin alma ${ }^{30}$.

En la misma crisi, dirá poco más adelante: «-¿Cómo que qué importa? -levantó la voz el cortesano-. ¡Qué linda flema la vuestra! Mucha Alemania gastáis». Y Evaristo Correa Calderón anota las siguientes palabras de RomeraNavarro: «No deja de ser original este gastar Alemania, por gastar flema» ${ }^{31}$.

Cuando los peregrinos descubren la corte del Saber, estaba esperándoles un raro personaje (por su poca abundancia), todo sesos, es decir, todo cordura: «Él era castellano en lo sustancial, aragonés en lo cuerdo, portugués en lo juicioso, y todo español en ser hombre de mucha sustancia» ${ }^{32}$. Anda parejas Gracián con Huarte en cuanto a dar la preeminencia al carácter español, oponiéndolo con total crudeza a sus vecinos europeos, como cuando en la crisi séptima comenta: «Había chimeneas de todos modos, unas a la francesa, muy disimuladas y angostas, otras a la española, muy campanudas y huecas, para que aun en esto se muestre la natural antipatía destas dos naciones opuestas en todo, en el vestir, en el comer, en el andar y hablar, en los genios e ingenios $»^{33}$. Podríamos eternizarnos en los ejemplos del Criticón, pero lo considero innecesario.

Que el melancólico es el carácter propio de los españoles parecen tenerlo claro los europeos del siglo XVII, y es cosa asumida por los mismos implicados. Si nuestra mejor literatura coincide con la exaltación europea del tema melancólico, resulta natural que dicha moda haya quedado prendida en nuestras mejores composiciones. Pero ¿es sólo eso? ¿O más bien el carácter melancólico español, previo y bien conocido, potenció los resultados artísticos? De ser así, todo nos venía de cara: el auge de la lengua castellana, la consolidación del Imperio, la moda de nuestro carácter melancólico.

Cuando Unamuno dedica un artículo suyo a hablar De las tristezas españolas: la acedía, comenta el parecer de los extranjeros sobre el carácter español en estos términos: «Es corriente leer en franceses que conocen las cosas de espíritu de España que hablan del castellano altier et morne; los ingleses le llaman proud and gloomy, orgulloso y triste» ${ }^{34}$.

\footnotetext{
http://es.wikisource.org/wiki/El_Critic\%C3\%B3n._Tercera_parte:_Crisi_3

Baltasar GraCián, El Criticón, III, Madrid, Espasa-Calpe, 1971, p. 82, notas 13-14.

http://es.wikisource.org/wiki/El_Critic\%C3\%B3n._Tercera_parte:_Crisi_6

http://es.wikisource.org/wiki/El_Critic\%C3\%B3n._Tercera_parte:_Crisi_7

Miguel de Unamuno, Obras Completas III. Nuevos Ensayos, Madrid, Escélicer, 1968, pp. 755-756.
} 
La melancolía estaba presente ya en nuestra literatura medieval: en las jarchas y en las cantigas de amigo. Está en la novela sentimental de Rodríguez del Padrón y de Diego de San Pedro. No podemos dejar de recordar al Calisto enamorado del comienzo de La Celestina, como un prototipo de melancólico por amor. Y, pegada a su actitud melancólica, la referencia del Arcipreste de Hita («et crei la fabrilla / Que dis: por lo pasado no estés mano en mejilla»). Comenzando el periodo áureo de nuestras letras, Garcilaso de la Vega (sin duda uno de nuestros más grandes poetas) es el gran melancólico de progenie cortesana, de aquel amor cortés que se inició en la Provenza y que se resume en su verso «no me podrán quitar el dolorido sentir» (Égloga I). Abierta la caja de los truenos por Garcilaso, otros muchos poetas contemporáneos y posteriores tomarán el testigo. Con burlas (como Hernando de Acuña, 1520-1580, en A una dama doliente de humor melancólico) y con veras (como Gutierre de Cetina, 1520-h. 1557, en el madrigal de oscuro sentimiento $A$ unos ojos). La lista es inmensa, sin que podamos olvidar a Herrera.

También la prosa española está en auge, y uno de los más fieles notarios es fray Antonio de Guevara (1480-1545); con un decir que hoy nos parece artificioso, pero que, como comenta Menéndez Pelayo, «es, sin duda, el [estilo] de la lengua hablada entonces, la hablada por un cortesano de extrema facilidad verbal» ${ }^{35}$. Su Marco Aurelio. Reloj de Príncipes (1529) fue el libro más leído en Europa después de la Biblia. En Inglaterra tuvo una influencia tan grande que dio origen al euphuismo ${ }^{36}$. Sus Epístolas familiares fueron lectura asidua del propio Montaigne. Pues bien, Guevara escribió también un Menosprecio de corte y alabanza de aldea (1539) que fragua uno de los grandes tópicos melancólicos, el del alejamiento. La obra denuncia la corte como lugar de corrupción y canta los placeres del campo. El tema del apartamiento de junto a los demás hombres se encuentra en el tópico del Demócrito melancólico, que conocemos muy bien, y entronca literariamente con el tema clásico de la literatura horaciana del beatus ille. Debemos decir también que la culminación renacentista-humanista de la relación entre el alejamiento de la corte como tema literario y el comportamiento melancólico lo encontramos en el libro de Burton tantas veces mencionado Anatomía de la melancolía.

Es, pues, el español Guevara quien crea el precedente del cortesano estigmatizado de las comedias barrocas:

Entre los famosos trabajos que en las cortes de los príncipes se pasan es que ninguno que allí reside puede vivir sin aborrecer o ser aborrecido, perseguir o

35 Ramón Menéndez Pidal, La lengua de Cristóbal Colón, cit., p. 63.

36 El eufuismo se caracteriza por el abuso de procedimientos retóricos así como por el empleo de un gran número de autoridades eruditas y de citas cultas. Se trata en realidad de una forma de conceptismo. 
ser perseguido, tener envidia o ser envidiado, murmurar o ser murmurado; porque allí a muchos quitan la gorra que les querrían más quitar la cabeza. No lo afirmo, mas sospécholo, que en las cortes de los príncipes son pocos, y muy pocos, y aun muy poquitos y muy repoquitos, los que se tienen entera amistad y se guardan fidelidad; porque allí, con tal que el cortesano haga su facto, poco se le da perder o ganar al amigo. [...] por manera que huelgan de meter en sus casas la guerra por echar de casa de otro la paz ${ }^{37}$.

En nuestras cortes y repúblicas, en las cuales hay ya tanto número de malos, se cometen tan atroces delitos, que lo que castigaban los antiguos por mortal, disimulan en este tiempo por venial ${ }^{38}$.

Ciertamente es el período Barroco el que muestra sumergidas a todas las artes españolas en la experiencia profunda de la melancolía. Lo constatamos en obras narrativas tan importantes como Guzmán de Alfarache o el ya mencionado Criticón. Igualmente hay ejemplos magníficos en la poesía barroca española. Es ésta la poesía del desengaño, vital en general y amoroso en particular. La descreencia en el hombre, que hemos visto en Gracián. Los grandes poetas (entre una pléyade de segundones magníficos) que son Quevedo y Góngora van a poetizar el reverso de la ilusión amorosa: «Déjame en paz, Amor tirano, / Déjame en paz», de la letrilla gongorina, o del soneto de Quevedo que dice:

Aguarda, riguroso pensamiento, / no pierdas el respeto a cuyo eres. / Imagen, sol o sombra, ¿qué me quieres? / Déjame sosegar en mi aposento. // Divina Tirsis, abrasarme siento; / sé blanda como hermosa entre mujeres; / mira que ausente como estás me hieres; / afloja ya las cuerdas al tormento. // Hablándote a mis solas me anochece; / contigo anda cansada el alma mía; / contigo razonando me amanece. // Tú la noche me ocupas y tú el día; / sin ti todo me aflige y entristece / y en ti mi mismo mal me da alegría ${ }^{39}$.

Ese «déjame sosegar en mi aposento» del primer cuarteto indica el deseo de retirada del mundo y de que triunfe la melancolía del que sin duda ha sido su gran antídoto desde que lo planteó el Problema XXX: Eros. Un Eros sin los ribetes pre-melancólicos de la poesía cortesana y petrarquista. La oscura concepción respecto a la vida en general, Quevedo nos la ofrece en sus más impresionantes poemas metafísicos:

«¡Ah de la vida!»... ¿Nadie me responde? / ¡Aquí de los antaños que he vivido! / La Fortuna mis tiempos ha mordido; / las Horas mi locura las esconde. // ¡Que sin poder saber cómo ni adónde, / la salud y la edad se hayan huido! /

37 http://www.filosofia.org/cla/gue/gueca15.htm

38 http://www.filosofia.org/cla/gue/gueca13.htm

39 Francisco de Quevedo, Obras Completas I. Poesía Original, Barcelona, Planeta, 197133, pp. 378-379. Cf. http://es.wikisource.org/wiki/Soneto_amoroso_(Aguarda,_riguroso_pensamiento) 
Falta la vida, asiste lo vivido, / y no hay calamidad que no me ronde. // Ayer se fue; mañana no ha llegado; / hoy se está yendo sin parar un punto; / soy un fue, y un será, y un es cansado. // En el hoy y mañana y ayer, junto / pañales y mortaja, y he quedado / presentes sucesiones de difunto ${ }^{40}$.

Pero al perfil melancólico español se une en estos momentos un aspecto fuertemente sociológico, la aparición de la conciencia de inferioridad española, que va a llevar, con el pasar de los siglos, a la crisis de la Generación del 98. Quevedo va a ser de los primeros en ver las grietas del Imperio ${ }^{41}$. Recordemos su España defendida, pero muy especialmente el conocidísimo Salmo XVII del Heráclito cristiano (no es casual este título):

Miré los muros de la patria mía, / si un tiempo fuertes, ya desmoronados, / de la carrera de la edad cansados, / por quien caduca ya su valentía. // Salíme al campo, vi que el sol bebía / los arroyos del hielo desatados, / y del monte quejosos los ganados, / que con sombras hurtó su luz al día. // Entré en mi casa, vi que, amancillada, / de anciana habitación era despojos; / mi báculo, más corvo y menos fuerte; // vencida de la edad sentí mi espada. / Y no hallé cosa en que poner los ojos / que no fuese recuerdo de la muerte ${ }^{42}$.

Se unen el tema de la patria, la España que se desmorona, con el huir del tiempo, el otro gran tema barroco y que despierta la más acerba melancolía. El tiempo que todo lo destruye está presente como tópico básico de varios de los poemas emblemáticos de nuestro siglo XVII. Uno de ellos es la canción del sevillano Rodrigo Caro, A las ruinas de Itálica. Más grande, una de las joyas de la poesía española de todos los tiempos, es la Epístola moral a Fabio, del capitán Fernández de Andrada.

Difícil nos resulta asumir para nuestro territorio las palabras de Jackson ${ }^{43}$, cuando dice que, en Europa, el siglo XVIII trae el gusto por hablar de la melancolía como conjunto de maneras, como coloración especial de la personalidad, como una afección del comportamiento propio de una mente superior. El intelectual (principalmente inglés) de modos afectados melancólicos, no cuadra con el intelectual y el político de la España dieciochesca (tan inevitablemente cerca de cuanto hemos comentado), y cuyo máximo ejemplo lleno de ambigüedades es Jovellanos, a quien todos nos representamos de inmediato en su despacho, mano en mejilla, según el cuadro de Goya.

40 Ibídem, p. 4. Cf. http://sonnets.spanish.sbc.edu/Quevedo_Ah.html

41 Nos servimos en gran parte de las reflexiones de Guillermo DíAz-PLAJA en su Tratado de las melancolías españolas, Madrid, Organización Sala Editorial, 1975, pp. 227-233.

${ }_{42}$ Francisco de Quevedo, Obras Completas I. Poesía Original, cit., pp. 31-32. Cf. http://es.wikisource.org/wiki/Mir\%C3\%A9_los_muros_de_la_patria_m\%C3\%ADa

43 Stanley W. JACKSON, Historia de la melancolía y la depresión, Madrid, Turner, 1989. 
Las bases sociopolíticas de la España de la melancolía no habían sido destruidas ni siquiera al adentrarnos en el siglo XX. En 1916, Unamuno, pilar de la llamada Generación del 98, concluye el artículo al que ya nos hemos referido:

¡Triste vida española, vida de hidalgos y licenciados locos, de pícaros y mendigos cuerdos! ¡Cuántas esperanzas tronchadas en flor! ¡Cuántos ingenios derretidos en un triste ocaso de acedía y de desengaño! Este año se celebrará, con toda la ridiculez y dota la ruindad de las celebraciones oficiales, el tercer centenario de la muerte melancólica del pobre Cervantes, el profeta del desengaño. ¿Habrá quien recuerde y comente las palabras brotadas del corazón acongojado del manco de Lepanto, que el ex loco Tomás Rodaja dijo al salir para siempre de la corte de las Españas? Son palabras de acedía, de triste acedía, de agrura, de dolorida agrura. Cierto es que Tomás Rodaja, el encogido y vergonzoso, fue como lo fue Cervantes, un orgulloso. Y, si no hubiera sido por el orgullo, ¿cómo habría podido vivir en el lóbrego convento de la patria?44

O cojámosle a Díaz-Plaja esta frase de Ortega y Gasset, según él, escalofriante y muy poco recordada: «Léase con un poco de buen sentido nuestro Parnaso del siglo XVII, e inténtese, partiendo de él, reconstruir el tipo de alma que lo ha fraguado. El que haga esta experiencia acabará echándose las manos a la cabeza, sobrecogido de espanto» ${ }^{45}$.

* David Pujante. Universidad de Valladolid.

** El autor ha remodelado su conferencia de abril de 2008 dada en el Hospital Psiquiátrico Dr. Villacián.

$44 \quad$ Ibídem, p. 758.

45 Citado por Guillermo DíAz-PlajA, Tratado de las melancolías españolas, p. 230. 